\title{
DYNAMICS OF STOICHIOMETRIC BACTERIA-ALGAE INTERACTIONS IN THE EPILIMNION *
}

\author{
HAO WANG ${ }^{\dagger}$, HAL L. SMITH ${ }^{\ddagger}$, YANG KUANG§ ${ }^{\S}$ AND JAMES J. ELSER
}

\begin{abstract}
Bacteria-algae interaction in the epilimnion is modeled with the explicit consideration of carbon (energy) and phosphorus (nutrient). Global qualitative analysis and bifurcation diagrams of this model are presented. We hypothesize that there are three dynamical scenarios determined by the basic reproductive numbers of bacteria and algae. Effects of key environmental conditions are examined through these scenarios and from systematic and extensive simulations. It is also shown that excessive sunlight will destroy bacterial communities. Bifurcation diagrams for the depth of epilimnion mimic the profile of Lake Biwa, Japan. Competition of bacterial strains are modeled to examine Nishimura's hypothesis that in severely P-limited environments such as Lake Biwa, P limitation exerts more severe constraints on the growth of bacterial groups with higher nucleic acid (HNA) contents, which allows low nucleic acid (LNA) bacteria to be competitive.
\end{abstract}

Key words. Stoichiometry, bacteria, cell quota, persistence, competitive system

1. Introduction. Stoichiometry is the accounting behind chemistry. It deals with the balance of multiple chemical elements in chemical reactions. Many chemical processes are effectively studied and modeled with the applications of some simple yet powerful stoichiometric constraints. Since biomass growth is a biochemical process, ubiquitous and natural stoichiometric constraints may also be useful for modeling species growth and interactions $([15,23,27,28])$. This concept forms the framework of the newly emerging research area of ecological stoichiometry, the study of the balance of energy and multiple chemical elements in ecological interactions ([37]).

It is observed that plant quality can dramatically affect the growth rate of herbivorous grazers and may even lead to their extinction. Specifically, if the quantity of an essential element in plant biomass is lower than the minimum threshold for its consumer, then the consumer's growth rate may suffer. This has been shown for both aquatic $([30,37])$, and terrestrial systems $([31])$. Stoichiometry-based population models explicitly model the highly varying nutritional quality of plant resources for consumer-resource dynamics.

Solar energy (for producing organic carbon) and nutrients (phosphorus, nitrogen, etc) are important factors regulating ecosystem characteristics and species density. Phosphorus is often a limiting nutrient for algal production in lakes ([11]). For example, in Lake Biwa, phosphorus is an extremely limiting element for both algal and bacterial growth. Lake Biwa is a large (surface area, $674 \mathrm{~km}^{2}$ ) and deep (maximum depth, $104 m$ ) lake located in the central part of Honshu Island, Japan. Nishimura et al. (2005) used flow cytometry to examine seasonal variations in vertical distributions of bacterioplankton in Lake Biwa. They hypothesized that in severely P-limited environments such as Lake Biwa, P limitation exerts more severe constraints on the

${ }^{*}$ The research of Hal L. Smith is partially supported by NSF Grant DMS 0414270, the research of Yang Kuang and James J. Elser is supported in part by DMS-0436341, DMS/NIGMS-0342388, and DEB-0516494.

${ }^{\dagger}$ Department of Mathematics and Statistics, Arizona State University, Tempe, AZ 852871804(wanghao@asu.edu)(corresponding author).

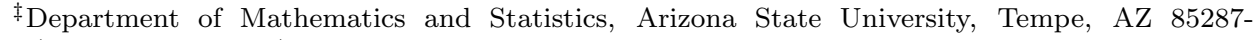
1804(halsmith@asu.edu).

$\S$ Department of Mathematics and Statistics, Arizona State University, Tempe, AZ 852871804(kuang@asu .edu).

『School of Life Sciences, Arizona State University, Tempe, AZ 85287-15011(j.elser@asu.edu). 


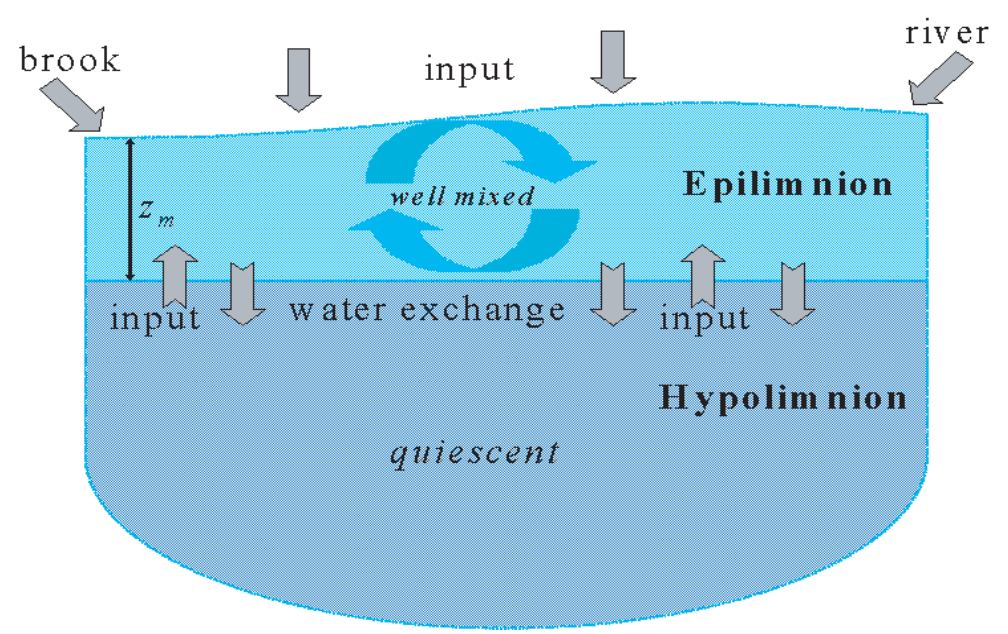

FIG. 1.1. The cartoon lake system for our mathematical modeling.

growth of bacterial groups with higher nucleic acid (HNA) contents, which allows low nucleic acid (LNA) bacteria to be competitive and become an important component of the microbial community. A main purpose of this paper is to examine this hypothesis theoretically.

The interaction between bacteria and algae in pelagic ecosystems is complex ([6]). Bacteria are nutrient-rich organisms whose growth is easily limited by nutrient supply and organic matter produced by plants and algae, which have very flexible stoichiometry compared to bacteria ([29]). Suspended algae, also called phytoplankton, live in almost all types of aquatic environments. Algae grow in open water by taking up nutrients such as phosphorus and nitrogen from the water and capturing energy from sunlight. Extra energy in the form of organic carbon can be exuded from algae during photosynthesis. Bacteria require dissolved organic carbon (DOC) as a source of energy and carbon. Hence, algae are an important source of DOC to bacteria. However, bacteria and algae compete with each other for phosphorus if bacteria are limited by phosphorus ([18]).

In temperate lakes, the water column is seasonally separated by a thermocline into two parts, epilimnion and hypolimnion (Fig. 1.1). The epilimnion is the upper warmer layer overlying the thermocline. It is usually well mixed. The hypolimnion is the bottom colder layer. The absorption and attenuation of sunlight by the water itself, by dissolved substances, and by algae are major factors controlling the potential photosynthesis and temperature. Solar energy, essential for algae, decreases rapidly with depth. Nutrients are redistributed from epilimnion to hypolimnion as the plankton detritus gradually sinks to lower depths and decomposes; the redistribution is partially offset by the active vertical migration of the plankton and by eddy diffusion across the thermocline ([19]). In many lakes, algal DOC exudation is a prime energy source for bacterial growth. To simplify the study of algal stimulation of bacterial growth, we assume below that algal DOC exudation is the only source for bacterial subsistence.

Algae dynamics in a lake system have been modeled by many researchers ([2, $8,9,20,21,22])$. Chemostat theory and experiments have been applied frequently to nutrient competition of bacteria $([4,14,34,35])$. For example, bacteria-algae 
TABLE 2.1

VARIABLES IN THE BACTERIA-ALGAE SYSTEM (2.2)

\begin{tabular}{|l|l|l|}
\hline var. & meaning & unit \\
\hline$A$ & algal carbon density & $\mathrm{mgC} / \mathrm{m}^{3}$ \\
$Q$ & algal cell quota (P:C) & $\mathrm{gP} / \mathrm{gC}(=\mathrm{mgP} / \mathrm{mgC})$ \\
$P$ & dissolved mineral phosphorus concentration & $\mathrm{mgP} / \mathrm{m}^{3}$ \\
$B$ & heterotrophic bacterial abundance & $\mathrm{mgC} / \mathrm{m}^{3}$ \\
$C$ & DOC concentration & $\mathrm{mgC} / \mathrm{m}^{3}$ \\
\hline
\end{tabular}

interaction was modeled by Bratbak and Thingstad (1985). Their work provides a useful framework to develop a more realistic model. In recent years, modeling stoichiometric food web systems gained much attention $([1,9,15,17,24,25,26$, $27])$. However, these models are not directly applicable to the phytoplankton-bacteria interaction. Our models, motivated by the experiments and hypotheses of Nishimura et al. (2005), can be viewed as an extension as well as a variation of the work of Diehl et al. (2005) where they modeled algal growth experiments subject to varying light and nutrient availability, but without bacteria.

In the following, we will model the ecological stoichiometry of bacteria-algae interactions in the epilimnion under the "well mixed" assumption $([2,20,21])$. We perform a global qualitative analysis and present bifurcation diagrams illustrating model behavior. We discuss the implications of these bifurcation diagrams and the basic reproductive numbers of bacteria and algae. Proofs of mathematical results are placed in the appendix. Competing bacterial strains are modeled to test some hypotheses of Nishimura et al. (2005). A brief discussion section concludes the paper.

2. Modeling Bacteria-Algae Interactions. Our model consists of five highly interconnected nonlinear differential equations, tracking the rates of change for algae, algal cell quota, dissolved mineral phosphorus, heterotrophic bacteria, and dissolved organic carbon. The algal growth is assumed to depend on the light intensity and phosphorus availability. This will be modeled according to the Lambert-Beer's law and the Droop equation. The rates of change for $Q, P, B$ are modeled according to standard approaches. In addition, algal sinking and water exchange between epilimnion and hypolimnion are included in the model. The challenge is to model the algal exudation of DOC, which is needed in the DOC equation.

According to Lambert-Beer's law, the light intensity at the depth $s$ of a water column with algal abundance $A$ is ([20])

$$
I(s, A)=I_{\text {in }} \exp \left[-\left(k A+K_{b g}\right) s\right] .
$$

The algal carbon uptake function takes the Monod form $\frac{I(s, A)}{I(s, A)+H}([9])$.

The epilimnion is well mixed overnight $([9,20])$. The depth-averaged algal growth function contains the factor (for carbon) $([2,20])$

$$
h(A) \equiv \frac{1}{z_{m}} \int_{0}^{z_{m}} \frac{I(s, A)}{I(s, A)+H} d s=\frac{1}{z_{m}\left(k A+K_{b g}\right)} \ln \left(\frac{H+I_{i n}}{H+I\left(z_{m}, A\right)}\right)
$$

and the Droop term (for phosphorus) $1-\frac{Q_{m}}{Q}$, where $Q_{m}$ is the minimum algal phosphorus cell quota and $Q$ is the actual algal phosphorus cell quota. 
TABLE 2.2

PARAMETERS IN BACTERIA-ALGAE SYSTEM (2.2)

\begin{tabular}{|c|c|c|c|}
\hline par. & meaning & value & ref. \\
\hline$I_{\text {in }}$ & light intensity at surface & $300 \mu \mathrm{mol}($ photons $) /\left(m^{2} \cdot s\right)$ & {$[9]$} \\
\hline$k$ & $\begin{array}{l}\text { specific light attenuation coeff. of } \\
\text { algal biomass }\end{array}$ & $0.0003-0.0004 m^{2} / m g C$ & {$[2,9]$} \\
\hline$K_{b g}$ & $\begin{array}{l}\text { background light attenuation co- } \\
\text { efficient }\end{array}$ & $0.3-0.9 / m$ & {$[2,9]$} \\
\hline$H$ & $\begin{array}{l}\text { h.s.c. for light-dependent algal } \\
\text { production }\end{array}$ & $120 \mu \mathrm{mol}($ photons $) /\left(\mathrm{m}^{2} \cdot \mathrm{s}\right)$ & {$[9]$} \\
\hline$z_{m}$ & depth of epilimnion & $>0 m, 30 m$ in Lake Biwa & {$[32]$} \\
\hline$Q_{m}$ & $\begin{array}{l}\text { algal cell quota at which growth } \\
\text { ceases }\end{array}$ & $0.004 g P / g C$ & {$[9]$} \\
\hline$Q_{M}$ & $\begin{array}{l}\text { algal cell quota at which nutrient } \\
\text { uptake ceases }\end{array}$ & $0.04 g P / g C$ & {$[9]$} \\
\hline$\rho_{m}$ & $\begin{array}{l}\text { maximum specific algal nutrient } \\
\text { uptake rate }\end{array}$ & $0.2-1 g P / g C /$ day & {$[2,9]$} \\
\hline$M$ & h.s.c. for algal nutrient uptake & $1.5 \mathrm{mgP} / \mathrm{m}^{3}$ & {$[9]$} \\
\hline$\mu_{A}$ & $\begin{array}{l}\text { maximum algal specific produc- } \\
\text { tion rate }\end{array}$ & $1.0 /$ day & {$[9]$} \\
\hline$l_{m}$ & $\begin{array}{l}\text { algal specific maintenance respira- } \\
\text { tion loss }\end{array}$ & $0.05-0.13 /$ day & {$[2,9]$} \\
\hline$\nu$ & algal sinking velocity & $0.05-0.25 \mathrm{~m} / \mathrm{day}$ & {$[2,9]$} \\
\hline$D$ & wate & $0.02 r$ & [2] \\
\hline$P_{\text {in }}$ & phosphorus input & $0-150 \mathrm{mg} P / \mathrm{m}^{3}$ & [2] \\
\hline$K_{P}$ & $\begin{array}{l}\text { P-dependent h.s.c. for bacterial } \\
\text { growth }\end{array}$ & $0.06-0.4 m g P / m^{3}$ & {$[4]$} \\
\hline$K_{C}$ & $\begin{array}{l}\text { C-dependent h.s.c. for bacterial } \\
\text { growth }\end{array}$ & $100-400 m g C / m^{3}$ & {$[5]$} \\
\hline$\mu_{B}$ & maximum bacterial growth rate & $1.5-4.0 /$ day & {$[4,5]$} \\
\hline$\theta$ & bacterial fixed cell quota & $0.0063-0.1585 \mathrm{mgP} / \mathrm{mgC}$ & {$[7,16]$} \\
\hline$\mu_{r}$ & bacterial respiration loss & $0.1-2.5 /$ day & {$[5,13]$} \\
\hline$\mu_{g}$ & grazing mortality rate of bacteria & $0.06-0.36 /$ day & {$[32]$} \\
\hline$r$ & $\begin{array}{l}\text { C-dependent yield constant for } \\
\text { bacterial growth }\end{array}$ & $0.31-0.75$ & {$[10,13]$} \\
\hline
\end{tabular}

'h.s.c.' stands for half-saturation constant.

Algal sinking takes place at the interface between epilimnion and hypolimnion, and its rate is negatively related to the volume of epilimnion, because with a larger volume there is relatively less proportion of total species abundances or element concentrations for sinking. For convenience, we assume that the algal sinking rate is inversely proportional to the mixing layer depth $z_{m}([2,9])$. $D$ is the water exchange rate across the interface between epilimnion and hypolimnion and between the epilimnion and the inflow and outflow (Fig. 1.1). We assume that there is a constant phosphorus concentration, $P_{i n}$, in the hypolimnion and in the inflow. Using the same reasoning as for algal sinking, we assume the water exchange is inversely proportional to $z_{m}$. We assume that bacteria have a fixed stoichiometry, since compared to algae, their elemental composition is relatively constant ([29]). We assume that bacterial 
growth functions for carbon and phosphorus take the Monod form: $f(P)=\frac{P}{K_{P}+P}$ and $g(C)=\frac{C}{K_{C}+C}$, where $K_{P}, K_{C}$ are half-saturation constants, respectively.

The exudation rate of DOC by algae is the difference between the potential growth rate attained when growth is not phosphorus-limited $\mu_{A} A \frac{1}{z_{m}} \int_{0}^{z_{m}} \frac{I(s, A)}{I(s, A)+H} d s$ and the actual growth rate $\mu_{A} A\left(1-\frac{Q_{m}}{Q}\right) \frac{1}{z_{m}} \int_{0}^{z_{m}} \frac{I(s, A)}{I(s, A)+H} d s$, which gives us the form $\mu_{A} A \frac{Q_{m}}{Q} \frac{1}{z_{m}} \int_{0}^{z_{m}} \frac{I(s, A)}{I(s, A)+H} d s$. This actually assumes that algae always fix carbon at rate $\mu_{A} A \frac{1}{z_{m}} \int_{0}^{z_{m}} \frac{I(s, A)}{I(s, A)+H} d s$ and then have to dispose of excessive carbon. As in ([9]), we assume that the algal phosphorus uptake rate is $\rho(Q, P)=$ $\rho_{m}\left(\frac{Q_{M}-Q}{Q_{M}-Q_{m}}\right) \frac{P}{M+P}$. At the minimum cell quota, the specific phosphorus uptake rate is just a saturating function of $P$. At the maximum cell quota, there is no uptake. The algal cell quota dilution rate is proportional to the algal growth rate ([2]).

The assumptions above yield the following bacteria-algae interaction system.

$$
\begin{aligned}
& \frac{d A}{d t}=\underbrace{\mu_{A} A\left(1-\frac{Q_{m}}{Q}\right) \frac{1}{z_{m}} \int_{0}^{z_{m}} \frac{I(s, A)}{I(s, A)+H} d s}_{\text {algal growth limited by nutrient and energy }}-\underbrace{l_{m} A}_{\text {respiration }}-\underbrace{\frac{\nu+D}{z_{m}} A}_{\text {sinking and exchange }} \\
& \frac{d Q}{d t}=\underbrace{\rho(Q, P)}_{\text {replenishment }}-\underbrace{\mu_{A} Q\left(1-\frac{Q_{m}}{Q}\right) \frac{1}{z_{m}} \int_{0}^{z_{m}} \frac{I(s, A)}{I(s, A)+H} d s}_{\text {dilution due to growth }} \\
& \frac{d P}{d t}=\underbrace{\frac{D}{z_{m}}\left(P_{\text {in }}-P\right)}_{\text {P input and exchange }}-\underbrace{\rho(Q, P) A}_{\text {P consumption by algae }}-\underbrace{\theta \mu_{B} B f(P) g(C)}_{\mathrm{P} \text { consumption by bacteria }} \\
& \frac{d B}{d t}=\underbrace{\mu_{B} B f(P) g(C)}_{\text {bacterial growth }}-\underbrace{\left(\mu_{r}+\mu_{g}\right) B}_{\text {respiration and grazing }}-\underbrace{\frac{D}{z_{m}} B}_{\text {exchange }} \\
& \frac{d C}{d t}=\underbrace{\mu_{A} A \frac{Q_{m}}{Q} \frac{1}{z_{m}} \int_{0}^{z_{m}} \frac{I(s, A)}{I(s, A)+H} d s}_{\text {DOC exudation from algae }}-\underbrace{\frac{1}{r} \mu_{B} B f(P) g(C)}_{\text {DOC consumption by bacteria }}-\underbrace{\frac{D}{z_{m}} C}_{\text {exchange }} .
\end{aligned}
$$

In the rest of this paper, we assume the following parameter values (with units and sources given in Table 2.2) for numerical simulations: $I_{\text {in }}=300, k=0.0004$, $K_{b g}=0.3, H=120, z_{m}=30, Q_{m}=0.004, Q_{M}=0.04, \rho_{m}=0.2, M=1.5, \mu_{A}=1$, $l_{m}=0.1, \nu=0.25, D=0.02, P_{i n}=120, K_{P}=0.06, K_{C}=100, \mu_{B}=3, \theta=0.1$, $\mu_{r}=0.2, \mu_{g}=0.1, r=0.5$. These specific values are taken from $[2,9]$, or selected inside the reasonable ranges (see Table 2.2).

Our first theorem states that there is a bounded set which all solutions of the system (2.2) eventually enter.

TheOREM 1. The system (2.2) is dissipative. 
3. Algae Dynamics. In order to have a comprehensive understanding of the model $(2.2)$, we study first the algae dynamics without bacteria $(B=0)$.

$$
\begin{aligned}
\frac{d A}{d t} & =\mu_{A} A\left(1-\frac{Q_{m}}{Q}\right) \frac{1}{z_{m}} \int_{0}^{z_{m}} \frac{I(s, A)}{I(s, A)+H} d s-l_{m} A-\frac{\nu+D}{z_{m}} A \equiv A \Psi(A, Q) \\
\frac{d Q}{d t} & =\rho(Q, P)-\mu_{A} Q\left(1-\frac{Q_{m}}{Q}\right) \frac{1}{z_{m}} \int_{0}^{z_{m}} \frac{I(s, A)}{I(s, A)+H} d s \\
\frac{d P}{d t} & =\frac{D}{z_{m}}\left(P_{i n}-P\right)-\rho(Q, P) A .
\end{aligned}
$$

From (2.1), we recall that

$$
h(A)=\frac{1}{z_{m}} \int_{0}^{z_{m}} \frac{I(s, A)}{I(s, A)+H} d s .
$$

It is decreasing in $A$, and $0<h(A)<1$. Furthermore, $A h(A)$ is increasing in $A$. Biologically meaningful initial conditions are given by $A(0)>0, Q_{m} \leq Q(0) \leq Q_{M}$, $P(0) \geq 0$. We analyze this system on the positively invariant set

$$
\Omega=\left\{(A, Q, P) \in \mathbb{R}_{+}^{3} \mid A \geq 0, Q_{m} \leq Q \leq Q_{M}, P \geq 0\right\} .
$$

Obviously the set where $A=0$ is invariant for the system. It is easy to see that $Q_{m}<Q<Q_{M}$ whenever $Q_{m}<Q(0)<Q_{M}$; that is, the cell quota stays within the biologically confined interval.

There can be two types of steady state solutions for system (3.1): the algae extinction steady state $E_{0}=\left(0, \hat{Q}, P_{i n}\right)$, where

$$
\hat{Q}=\frac{\beta\left(P_{i n}\right) Q_{M}+\mu_{A} Q_{m} h(0)}{\beta\left(P_{i n}\right)+\mu_{A} h(0)}>0 \quad \text { with } \quad \beta(P)=\frac{\rho_{m}}{Q_{M}-Q_{m}} \frac{P}{M+P}
$$

and positive steady $\operatorname{state}(\mathrm{s}) E^{*}=(\bar{A}, \bar{Q}, \bar{P})$ with $\Psi(\bar{A}, \bar{Q})=0$.

The standard computation shows that the basic reproductive number for algae is

$$
R_{0}=\frac{\mu_{A} \beta\left(P_{i n}\right)\left(Q_{M}-Q_{m}\right) h(0)}{\left(\beta\left(P_{i n}\right) Q_{M}+\mu_{A} Q_{m} h(0)\right)\left(l_{m}+\frac{\nu+D}{z_{m}}\right)}=\frac{\mu_{A} h(0)\left(1-Q_{m} / \hat{Q}\right)}{l_{m}+\frac{\nu+D}{z_{m}}} .
$$

Here $h(0)=\frac{1}{z_{m} K_{b g}} \ln \left(\frac{H+I_{i n}}{H+I_{i n} \exp \left(-z_{m} K_{b g}\right)}\right)$ is the potential average sunlight intensity in the epilimnion without algal shading. Indeed, $R_{0}$ is calculated from $\Psi(0, \hat{Q})$ so that $R_{0}>1 \Leftrightarrow \Psi(0, \hat{Q})>0$. $R_{0}$ is the average amount of new algae produced by one unit of algae (measured in carbon content) during the algal life span in the epilimnion. It is an indicator of algal viability. Part of Theorem 2 states that $R_{0}$ is an indicator for the local stability of $E_{0}$.

We observe that increasing sunlight input or phosphorus input enhances algal viability, since $\frac{\partial R_{0}}{\partial I_{i n}}=\frac{\partial R_{0}}{\partial h(0)} \frac{\partial h(0)}{\partial I_{i n}}>0$ and $\frac{\partial R_{0}}{\partial P_{i n}}=\frac{\partial R_{0}}{\partial \beta\left(P_{i n}\right)} \frac{\partial \beta\left(P_{i n}\right)}{\partial P_{i n}}>0$. Weakening water exchange enhances algal viability, since $\frac{\partial R_{0}}{\partial D}<0$.

Theorem 2 is our main mathematical result. When $R_{0}<1$, we establish the local and global stability of $E_{0}$, which is equivalent to saying that algae will die out. It 


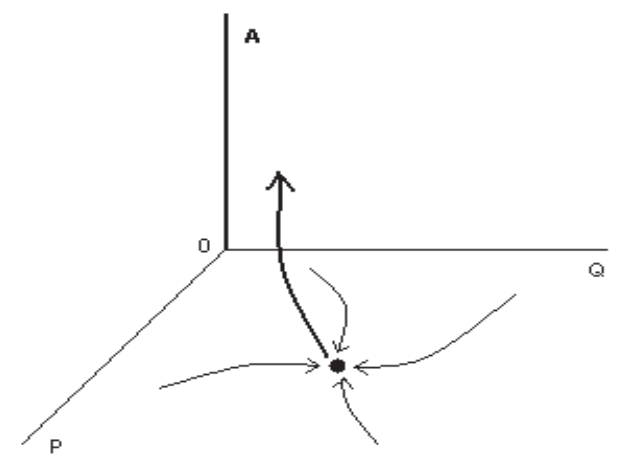

FIG. 3.1. Algae dynamics phase space when $R_{0}>1$. The algae extinction equilibrium $E_{0}=$ $\left(0, \hat{Q}, P_{\text {in }}\right)$ is globally attracting on the subspace $\Omega_{2}=\{x \in \Omega \mid A=0\}$ but a uniform weak repeller for $\Omega_{1}=\{x \in \Omega \mid A \neq 0\}$, and $A$ is persistent in this case.

can be shown that there is no positive equilibrium $E^{*}$ when $R_{0}<1$, in which case the existing results of general competitive systems can be applied to prove the global stability of $E_{0}$. When $R_{0}>1$, we prove that $E_{0}$ is unstable, algae are uniformly persistent, and there is a unique positive steady state $E^{*}$.

THEOREM 2. If $R_{0}<1, E_{0}$ is locally asymptotically and globally asymptotically stable. $R_{0}>1$ implies that $E_{0}$ is unstable, there exists a unique positive equilibrium $E^{*}$, and algae uniformly persist: there exists $\epsilon>0$ such that

$$
\liminf _{t \rightarrow \infty} A(t)>\epsilon
$$

for all solutions with $A(0)>0$.

In the following, we show that the global stability of $E^{*}$ is true in two special cases. It is known that the algal cell quota changes on much faster timescale than the algal (carbon) biomass and the nutrient ([23]). Additionally, since $d Q / d t$ is linear in $Q$, there is a unique solution to $d Q / d t=0$. Hence, the fast-slow approximation is achieved by setting $d Q / d t=0$ and substituting the solution of $d Q / d t=0$ into the other equations. Then the following theorem holds.

THEOREM 3. $E^{*}$ is globally asymptotically stable for the planar system obtained from the system (3.1) by setting $d Q / d t=0$, when $R_{0}>1$.

The next theorem gives a partial result of global stability of $E^{*}$.

THEOREM 4. $E^{*}$ is globally asymptotically stable when $R_{0}>1$ and $l_{m}=\nu=0$.

The property that a locally asymptotically stable (in linear approximation) steady state is globally attracting is an open condition in parameters $([36])$. Hence, $E^{*}$ is still globally asymptotically stable for small positive $l_{m}$ and $\nu$.

Our main mathematical results for the system (3.1) are briefly expressed by the phase space diagram (Fig.3.1) for the case $R_{0}>1$. Typical solutions are simulated in Fig. 3.2 for different depths of epilimnion. Algal abundance is negatively related 

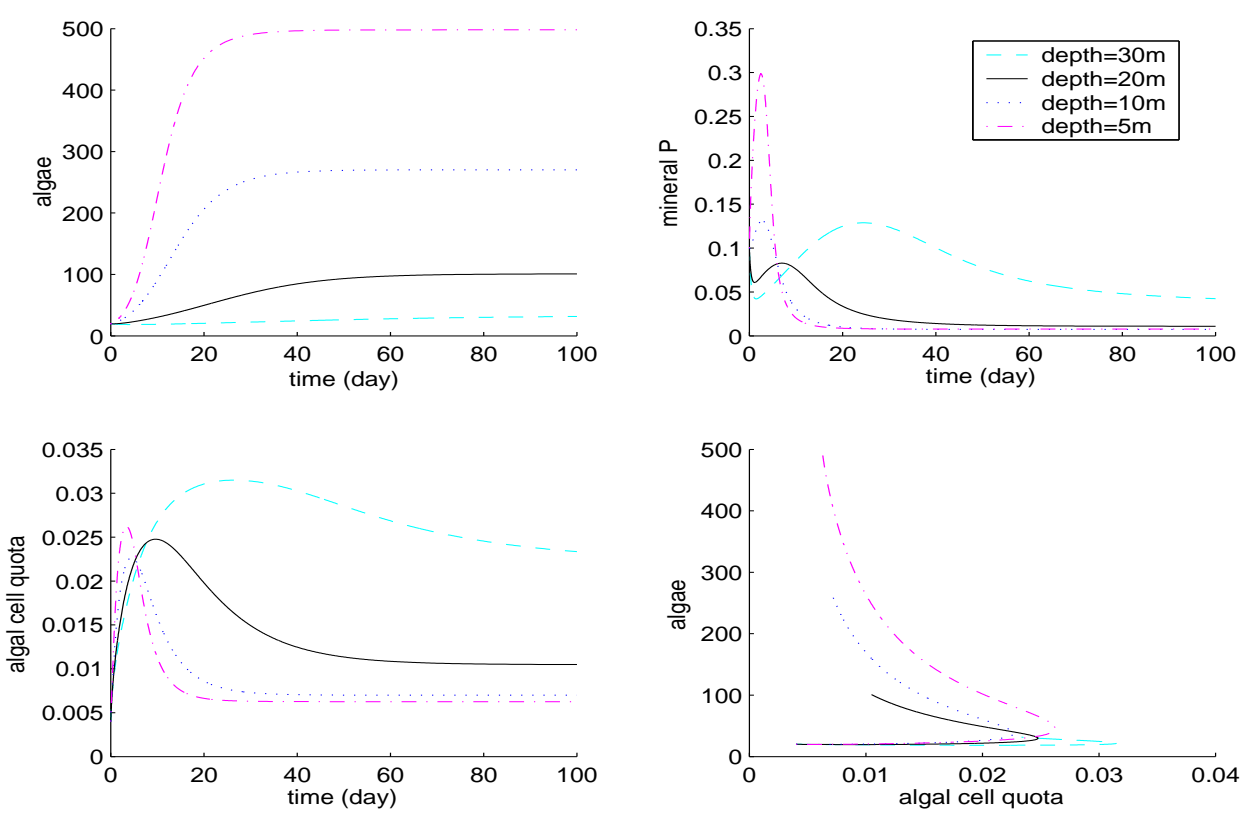

FIG. 3.2. Algae dynamics without bacteria with respect to different depths of the mixing layer: All the variables approach the positive equilibrium in about two months. The simulation benefited from the explicit expression of $h(A)$ given in (2.1).

to the depth because the average sunlight intensity in the epilimnion is lower when the epilimnion is deeper. The eventual $\mathrm{P}$ concentration is relatively large when the epilimnion is deep whereas the eventual concentration is small when it is shallow. Eventual concentrations at the depths $5 \mathrm{~m}, 10 \mathrm{~m}, 20 \mathrm{~m}$ are similar and low, which indicates that $\mathrm{P}$ becomes limiting in a shallow epilimnion. In contrast, the algal cell quota is positively related to epilimnion depth. This is due to the fact that the algal cell quota is positively related to the $\mathrm{P}$ concentration. Hence, epilimnion depth has two influences on algae in our simulation: it is positively related to $\mathrm{P}$ (at least in Fig. 3.2) and negatively related to the average sunlight intensity through the average light uptake integral term. In the case of Fig. 3.2, if $\mathrm{C}$ has a larger effect than $\mathrm{P}$, then algal abundance is negatively related to the depth. It is not clear whether or not algal abundance can be positively related to depth when $\mathrm{P}$ is more limited than $\mathrm{C}$ in some lakes. The algae-quota phase plane shows that algae and their cell quota are positively related in the very beginning, but they are negatively related eventually, demonstrating a general phenomenon of "larger quantity leads to lower quality". The bifurcation diagram with respect to the mixing layer depth (Fig. 3.3) illustrates that algae love shallower epilimnions and also illustrates our mathematical findings.

4. Bacteria-Algae Interaction Dynamics. We now return to the original bacteria-algae system (2.2). We analyze this system on the positively invariant set

$$
\Omega=\left\{(A, Q, P, B, C) \in \mathbb{R}_{+}^{5} \mid A \geq 0, Q_{m} \leq Q \leq Q_{M}, P \geq 0, B \geq 0, C \geq 0\right\} .
$$

The system (2.2) may have three types of equilibria: the extinction steady state $e_{0}=\left(0, \hat{Q}, P_{i n}, 0,0\right)$, the bacteria extinction only steady state $e_{1}=(\bar{A}, \bar{Q}, \bar{P}, 0, \bar{C})$ and the coexistence steady state(s) $e^{*}$ with all components positive. We can calculate the 


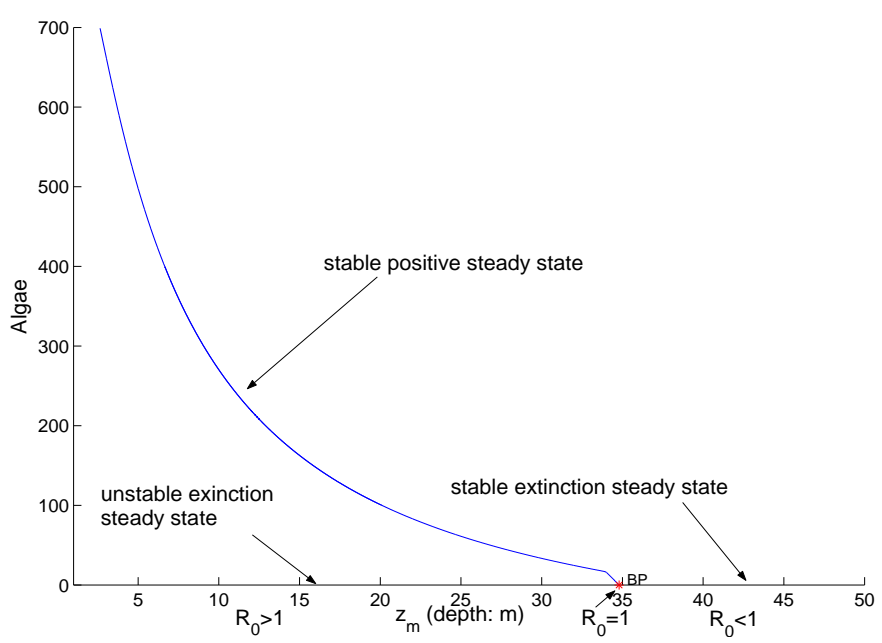

FIG. 3.3. Bifurcation diagram for algae dynamics without bacteria. The shallower the better for algae in the algae system 3.1. This bifurcation diagram confirms our mathematical findings. When $R_{0}>1$, the algae extinction equilibrium is unstable, and the only positive equilibrium appears to be globally attractive. The branching point occurs at $R_{0}=1$. When $R_{0}<1$, there is no positive equilibrium and the algae extinction equilibrium is globally attracting. This numerical result is generated by the continuation software 'MatCont' in MATLAB.

basic reproductive number for bacteria, $R_{1}$, by linearizing about $e_{1}$. We obtain

$$
R_{1}=\frac{\mu_{B} f(\bar{P}) g(\bar{C})}{\mu_{r}+\mu_{g}+\frac{D}{z_{m}}}
$$

where $\bar{C}=\frac{\mu \bar{A} z_{m}}{D} \frac{Q_{m}}{\bar{Q}} h(\bar{A})$ and $\bar{P}, \bar{A}, \bar{Q}$ are components of $E^{*}$ in the system (3.1). This number is defined under the assumption $R_{0}>1$. When $R_{0}<1$, we have proved that there is no positive equilibrium in system (3.1), which means at least one of $\bar{P}, \bar{A}$, $\bar{Q}$ is undefined or out of the region of interest. Biologically, $R_{1}$ is the average biomass of new bacteria produced by one unit of bacterial biomass during the bacterial life span in epilimnion. $R_{1}$ should be an indicator for the local stability of $e_{1}$; hence, $R_{1}$ is an indicator for the bacterial viability when $R_{0}>1$.

A simple sufficient condition for the extinction of both algae and bacteria is given in the next theorem.

Theorem 5. When $\mu_{A} h(0)<\frac{D}{z_{m}}\left(\Leftrightarrow \frac{\mu_{A}}{K_{b g}} \ln \left(\frac{H+I_{\text {in }}}{H+I_{\text {in }} \exp \left(-z_{m} K_{b g}\right)}\right)<D\right)$, both algae and bacteria will die out, i.e. $\lim _{t \rightarrow \infty} A(t)=\lim _{t \rightarrow \infty} B(t)=0$ for all nonnegative initial conditions.

It is easy to observe that $R_{0}<\frac{\mu_{A} h(0)}{D / z_{m}}$. Hence $\mu_{A} h(0)<\frac{D}{z_{m}}$ implies $R_{0}<1$.

Fig. 4.2 confirms both species go extinct when $R_{0}<1$, a weaker condition than the condition $\mu_{A} h(0)<\frac{D}{z_{m}}$ in Theorem 5. The line-filled region expands rapidly when the sunlight increases past $800 \mu \mathrm{mol}$ (photons) $/\left(\mathrm{m}^{2} \mathrm{~s}\right)$. This suggests that high 


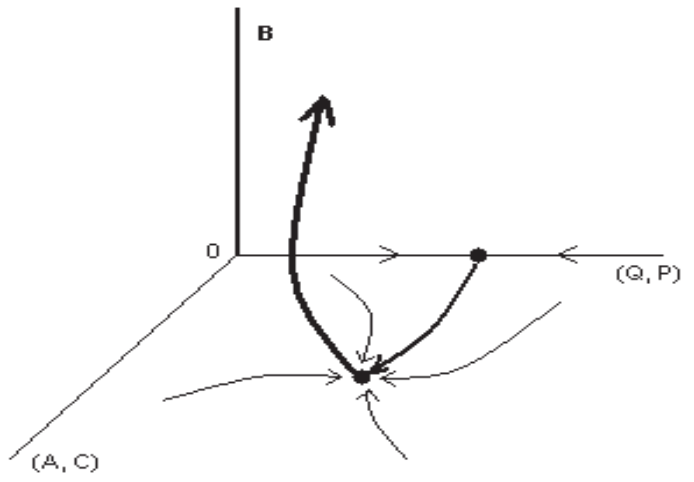

FIG. 4.1. An abstract phase space diagram for system (2.2) when $R_{0}>1$ and $R_{1}>1$. $Q, P$ are placed on one axis (say x-axis), $A, C$ are placed on another axis (say $y$-axis) and $B$ is on the vertical axis (z-axis). Extinction equilibrium $e_{0}=\left(0, \hat{Q}, P_{i n}, 0,0\right)$ is globally attracting on the subspace $\{x \in \Omega \mid A=B=C=0\}$, but a repeller for $\Omega_{2}=\{x \in \Omega \mid B=0\}$. Bacteria extinction only equilibrium $e_{1}=(\bar{A}, \bar{Q}, \bar{P}, 0, \bar{C})$ is globally attracting on the subspace $\Omega_{2}$, but a repeller for $\Omega_{1}=\{x \in \Omega \mid B \neq 0\}$. Bacteria persist, and at least one coexistence equilibrium exists.

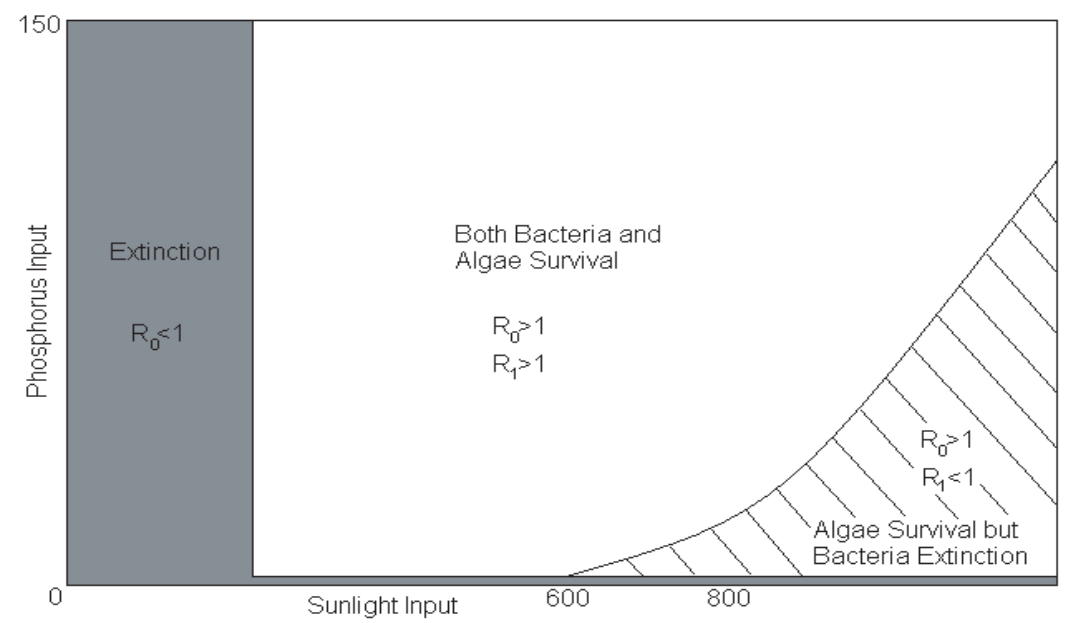

FIG. 4.2. Regions of $P_{\text {in }}$ versus $I_{\text {in }}$ for survival and extinction of bacteria and algae. Both algae and bacteria go extinct $\left(R_{0}<1\right)$ in the grey region. Both algae and bacteria survive $\left(R_{0}>1, R_{1}>1\right)$ in the white region. Algae survive but bacteria go extinct $\left(R_{0}>1, R_{1}<1\right)$ in the line-filled region. We run simulations of the system (2.2) for each pair of $\left(I_{i n}, P_{i n}\right)$, and then put the point in the grey region if both $A$ and $B$ go to zero, in the white region if both persist, and in the line-filled region if $A$ persists but $B$ goes to zero.

light intensity can negatively affect bacteria, even driving them to extinction due to competition with algae. Hence, the balance of light and nutrient is significant for the lake system, which is in agreement with "light:nutrient" hypothesis ([38]).

Branching points in Fig. 3.3 and Fig. 6.1 are identical, since all of them are determined by the same condition $R_{0}=1$. $R_{1}$ does not affect this branching point, since $R_{1}$ is defined only if $R_{0}>1$. $R_{0}>1$ implies $R_{1}>1$ in the white region of Fig. 4.2). Upon existent mathematical results, we hypothesize that there are three types of dynamics. (1) $R_{0}>1, R_{1}>1$ ensure the persistence of species (white region in 

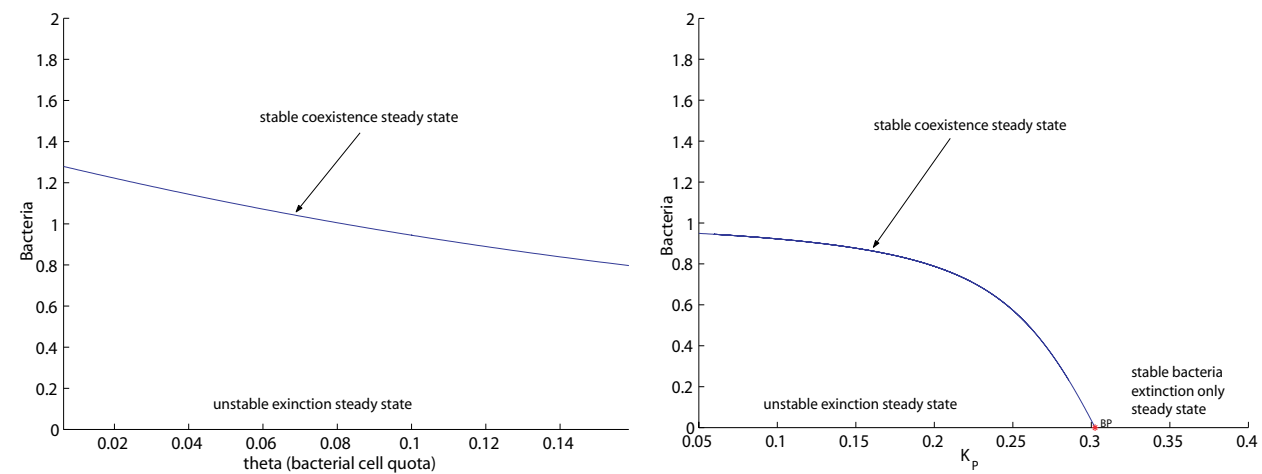

(a) Bacteria vs $\theta$ : supporting 'P requirement' (b) Bacteria vs $K_{P}$ : supporting 'nutrient uptake hypothesis. $\theta$ is the bacterial homeostasis cell efficiency' hypothesis. $K_{P}$ is the P-dependent quota.

half-saturation constant for the bacterial growth.

FIG. 5.1. We examine Nishimura's hypotheses by system (2.2).
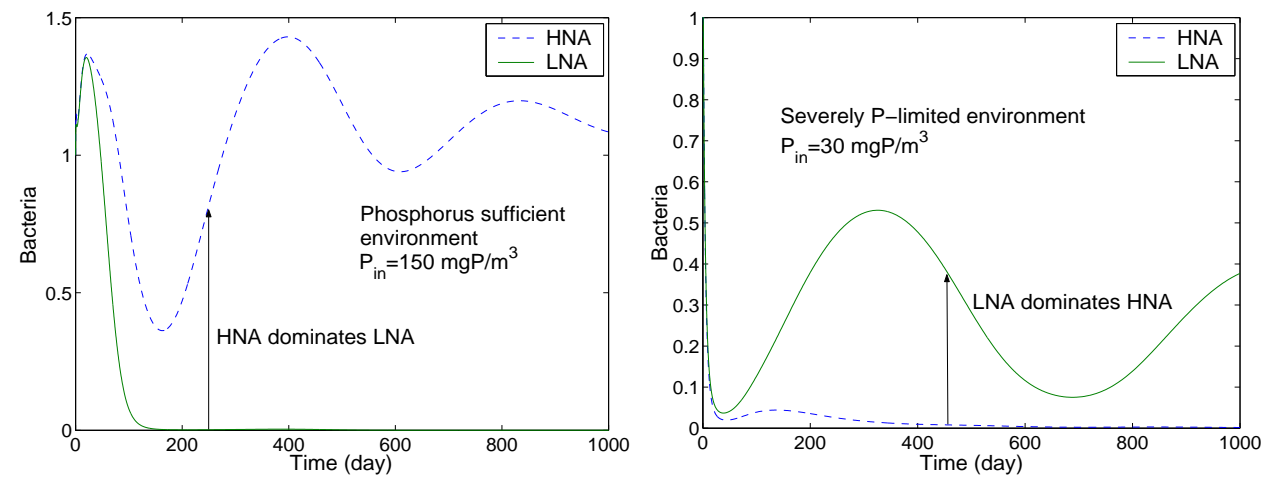

FIG. 5.2. Under different lake environments, a different bacterial strain dominates. $\mu_{1}=$ $4, \mu_{2}=2, K_{1}=0.15, K_{2}=0.06, \theta_{1}=0.1, \theta_{2}=0.05$ with same units in Table 2.2.

Fig. 4.2); (2) $R_{0}>1, R_{1}<1$ enable the persistence of algae but the extinction of bacteria (line-filled region in Fig. 4.2); (3) $R_{0}<1$ leads to the extinction of all species (grey region in Fig. 4.2).

5. Competing Bacterial Strains. In lake ecosystems, bacteria comprise the most important trophic level for processing dissolved organic matter (DOM) and consume almost half of the primary production ([32]). Most existing studies have treated bulk bacterial communities as a homogeneous pool, even though they consist of diverse subgroups that differ in metabolic state, DOM use, growth rate, susceptibility to grazing and phylogenetic affiliations. One of the challenges for aquatic microbial ecology is to clarify variations and regulation of different bacterial subgroups in order to better understand the internal dynamics of the bacterioplankton "black box". 
Growth characteristics and ecological roles of LNA bacteria are controversial. Some previous studies have claimed that LNA bacteria represent less active, dormant, or even dead cells. However, Nishimura et al. ([32]) found that the growth rates of LNA bacteria were comparable to or even exceeded HNA bacteria in Lake Biwa, Japan. This is probably because LNA bacteria have higher nutrient uptake efficiencies (this means bacteria take up nutrients efficiently even at very low external concentrations, i.e. have a low half-saturation constant for $\mathrm{P}$ ) and lower requirements for $\mathrm{P}$ (this means less $\mathrm{P}$ per unit carbon is needed, or a smaller cell quota). An important implication of this scenario is that LNA bacteria, under severe P-limitation conditions, represent an "active" subgroup that out competes HNA bacteria and hence may play an important role in the functioning of the microbial loop ([32]). In fact, both these two seemingly contradictory statements can be correct under different situations. One of our main motivations for this work is to examine these statements theoretically.

To examine the statement that 'LNA bacteria have lower requirements for P', we plot the bifurcation diagram of the bacterial variable with respect to the cell quota parameter $\theta$ for the system (2.2). This is done in Fig. 5.1 (a). Clearly, this figure supports the 'P requirement' hypothesis, since a lower bacterial cell quota gives higher bacterial abundance at equilibrium. The second statement 'LNA bacteria have higher nutrient uptake efficiencies' is supported by Fig. 5.1 (b), which has higher sensitivity than Fig. 5.1 (a). This seems to suggest that 'nutrient uptake efficiency' is probably the key factor for LNA bacteria to dominate HNA bacteria near the surface since this is where $\mathrm{P}$ is most limiting.

To examine Nishimura's hypothesis, we model the competition of two bacterial strains, HNA bacteria $\left(B_{1}\right)$ and LNA bacteria $\left(B_{2}\right)$ and assume these two strains are heterogeneous in $\mathrm{P}$ usage and the maximum growth rate, but homogeneous in C usage. Elser et al. ([12, 37]) have proposed the "Growth Rate Hypothesis" to explain variation among organisms in biomass $\mathrm{C}: \mathrm{P}$ and $\mathrm{N}: \mathrm{P}$ ratios. The Growth Rate Hypothesis states that differences in organismal $\mathrm{C}: \mathrm{N}: \mathrm{P}$ ratios are caused by differential allocations to RNA necessary to meet the protein synthesis demands of rapid rates of biomass growth and development (p144, [37]). Due to the Growth Rate Hypothesis, the bacterial cell quota is strongly correlated to the maximum growth rate; that is, $\theta_{1} / \theta_{2}=\iota \mu_{1} / \mu_{2}$, where $\iota$ is a positive constant. For convenience, we assume $\theta_{1} / \theta_{2}=\mu_{1} / \mu_{2}$. With these assumptions, the competition system takes the form

$$
\begin{aligned}
\frac{d A}{d t} & =\mu_{A} A\left(1-\frac{Q_{m}}{Q}\right) h(A)-l_{m} A-\frac{\nu+D}{z_{m}} A \\
\frac{d Q}{d t} & =\rho(Q, P)-\mu_{A} Q\left(1-\frac{Q_{m}}{Q}\right) h(A) \\
\frac{d P}{d t} & =\frac{D}{z_{m}}\left(P_{i n}-P\right)-\rho(Q, P) A-\left[\theta_{1} \mu_{1} B_{1} f_{1}(P)+\theta_{2} \mu_{2} B_{2} f_{2}(P)\right] g(C) \\
\frac{d B_{1}}{d t} & =\mu_{1} B_{1} f_{1}(P) g(C)-\left(\mu_{r}+\mu_{g}\right) B_{1}-\frac{D}{z_{m}} B_{1} \\
\frac{d B_{2}}{d t} & =\mu_{2} B_{2} f_{2}(P) g(C)-\left(\mu_{r}+\mu_{g}\right) B_{2}-\frac{D}{z_{m}} B_{2} \\
\frac{d C}{d t} & =\mu_{A} A \frac{Q_{m}}{Q} h(A)-\frac{1}{r}\left[\mu_{1} B_{1} f_{1}(P)+\mu_{2} B_{2} f_{2}(P)\right] g(C)-\frac{D}{z_{m}} C
\end{aligned}
$$




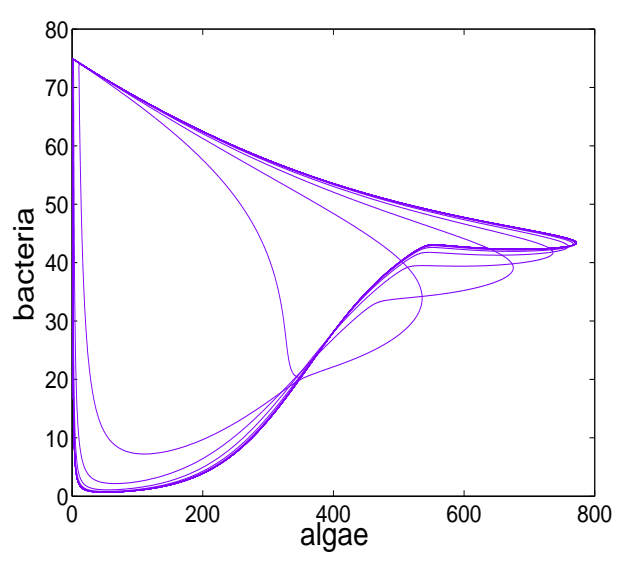

(a) Bacteria vs algae

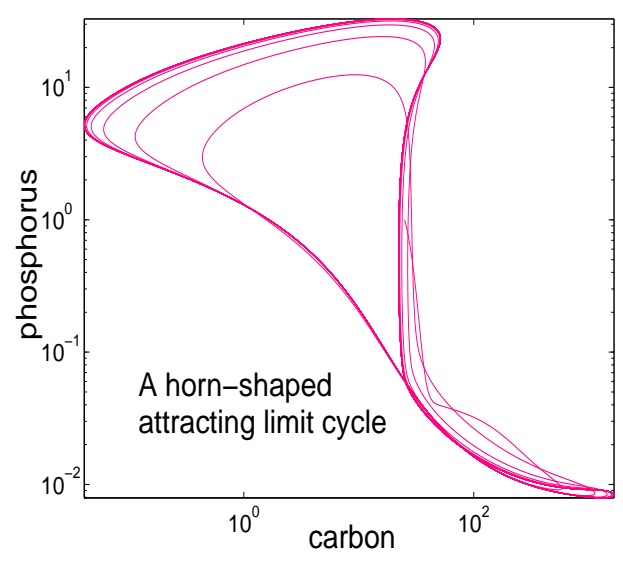

(b) $\mathrm{P}$ vs $\mathrm{C}$

FiG. 5.3. With shallow mixing layer $z_{m}=1$ and default values for other parameters, system (2.2) exhibit complex dynamics.

where $f_{i}(P)=\frac{P}{K_{i}+P}, i=1,2$. Since the maximum LNA bacteria growth rate is lower and LNA bacteria have higher nutrient uptake efficiencies, it is biologically reasonable to assume that $\mu_{1}>\mu_{2}, K_{1}>K_{2}$.

The positivity and dissipativity of the system (5.1) obviously hold and the proof can be formulated in a similar fashion as that of Theorem 1.

As we can see from Fig. 5.2, HNA bacteria grow faster than LNA bacteria whenever $\mathrm{P}$ is sufficient, simply because in such situations the maximum HNA bacteria growth rate is greater than that of LNA bacteria. But LNA bacteria grow faster than HNA bacteria whenever $\mathrm{P}$ is severely limited (Fig. 5.2), because LNA bacteria have higher nutrient uptake efficiencies and lower requirements for $\mathrm{P}$. Therefore, these seemingly conflicting phenomena can happen under distinct nutrient conditions.

We can seek the expression of the potential positive steady state of the system (5.1). From the bacterial equations, we have

$$
\mu_{i} f_{i}(P) g(C)=\left(\mu_{r}+\mu_{g}\right)+\frac{D}{z_{m}}
$$

for the potential positive steady state. Solving it for $P$, we obtain

$$
P=\frac{a K_{i}}{\mu_{i} g(C)-a}
$$

where $a=\left(\mu_{r}+\mu_{g}\right)+\frac{D}{z_{m}}$ is a constant. Assume the system (5.1) has a positive steady state, then $\mu_{i} g(C)>a$ holds for $i=1,2$. For a fixed $C$ level, the $P$ level for the potential positive steady state of that bacterial strain is increasing in $K_{i}$, but decreasing in $\mu_{i}$. Since $K_{2}$ is smaller, LNA bacteria have more chance to survive because of lower level of $P$ required to reach its potential positive steady state level. However, $\mu_{2}$ is also smaller, which can reduce LNA bacteria's chance to survive because of the higher level of $P$ required to obtain its potential positive steady state level. In other words, $K_{i}$ and $\mu_{i}$ work together in a nonlinear fashion. These arguments are only true for the case when a single steady state is globally attractive, in which case only one bacterial strain persists (see Fig. 5.2). These bacterial strains may coexist in the form of limit cycles, as periodic solutions are possible even for system (2.2) (for example, Fig. 5.3). 

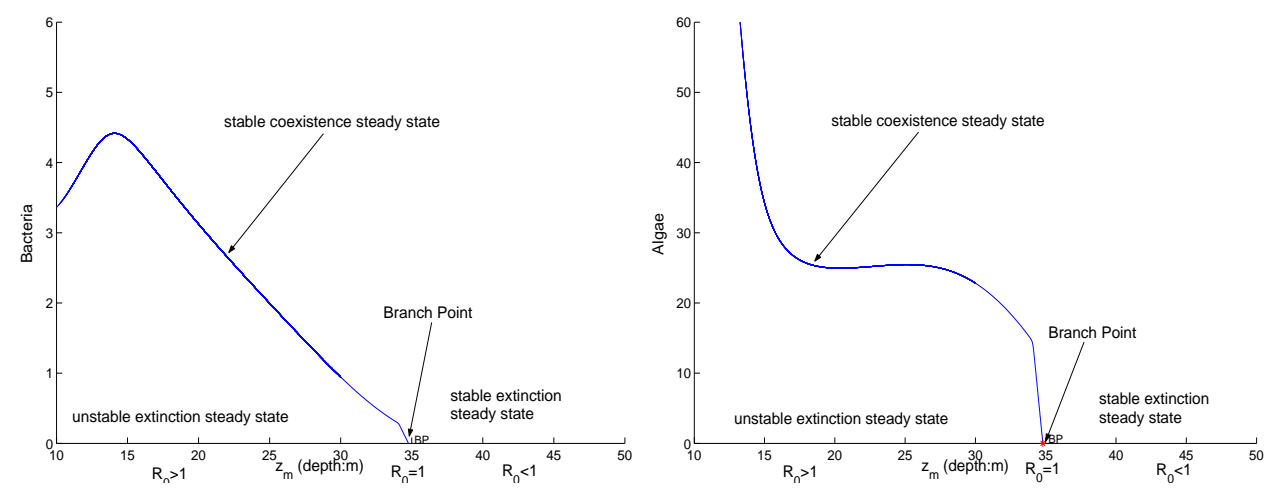

FIG. 6.1. Bifurcation diagrams of system (2.2) with respect to depth of epilimnion.

6. Discussion. Mechanistically formulated mathematical models of population dynamics are sought after since they often have advantages over phenomenologically derived ad hoc models in generating plausible and verifiable dynamics. However, the challenge of developing a mechanistic and predictive theory for biological systems is daunting. Exciting progress in understanding and modeling ecological systems in the last decade has been achieved through the application of the theory of ecological stoichiometry $([37])$ and the consideration of interactions between nutrient and light availability $([8,9,20,21,22])$. Our models (2.2) and (5.1), hybrids of mechanistic and phenomenological derivations and motivated by the experiments and hypotheses of Nishimura et al. (2005), continue this newly established tradition. They can be viewed as an extension as well as a variation of the work of Diehl et al. (2005) who modeled algal growth experiments subject to varying light and nutrient availability.

Our preliminary analytical results on system (2.2) demonstrate that it is mathematically interesting and our extensive bifurcation and numerical simulation work suggest that it is biologically sound.

We leave many mathematical questions open, including the global qualitative result below.

Conjecture. $E^{*}$ is globally asymptotically stable when $R_{0}>1$.

Theorem 3 and Theorem 4, together with the bifurcation diagram (Fig. 3.3) and the uniqueness of $E^{*}$, support the conjecture. This limiting case global stability result (Theorem 3) for the positive equilibrium suggests that the conjecture is true when the cell quota evolves on much faster timescale than other variables. Theorem 4 and its extension are pure mathematical results that give more credence to the conjecture.

Obviously, algae are favored by shallow epilimnia, sufficient sunlight and P inputs while bacteria are favored by medium depths of epilimnion and sunlight, and sufficient $\mathrm{P}$ input. With a larger $\mathrm{P}$ input, the ecosystem can thrive with more intensive sunlight input. Alternatively, with more intensive sunlight input, the algae-bacteria ecosystem may need more $\mathrm{P}$ input to be viable. When the epilimnion is very shallow $\left(z_{m}=1\right)$, the system (2.2) may generate complicated attractors such as that shown in Fig. 5.3. It can be said that a shallower epilimnion tends to be more transient and fragile compared to a deep one.

Bifurcation diagrams of bacteria and algae versus depth are shown in Fig. 6.1. 
From Fig. 6.1 (a) and (b), we observe that neither algae nor bacteria may survive in a very deep mixing layer $(>35 \mathrm{~m})$. In Lake Biwa, the northern lake with mean depth $43 \mathrm{~m}$ is much deeper than the southern lake with mean depth $4 \mathrm{~m}$. Our bifurcation diagrams (Fig. 6.1) try to mimic bacterial and algal abundances in Lake Biwa from southern site to northern site. According to these diagrams, bacteria to algae ratios in the south should be smaller than in the north. This numerical observation may be tested in the field.

The mathematical study of the more involved system (5.1) is even more complex and we thus opted to perform only numerical simulations to examine the hypotheses of Nishimura et al. (2005). Our bifurcation diagrams (Fig.5.1) suggest that higher nutrient uptake efficiencies of LNA bacteria is the key factor for LNA bacteria to dominate HNA bacteria in severely $\mathrm{P}$ limited lakes.

Acknowledgements We are grateful to the referees for their many helpful and insightful suggestions. We would like to thank Val Smith for introducing Nishimura et al.'s paper ([32]) to us, Irakli Loladze for an initial discussion and James Cotner for comments on the bacterial cell quota. We also thank Sebastian Diehl for his helpful suggestions, and James Grover for his valuable comments on parameter estimations and conclusions.

\section{REFERENCES}

[1] T. Andersen, Pelagic Nutrient Cycles: Herbivores as Sourced and Sinks for Nutrients, SpringerVerlag, Berlin (1997).

[2] S. A. Berger, S. Diehl, T.J. Kunz, D. Albrecht, A.M. Oucible and S. Ritzer, Light supply, plankton biomass, and seston stoichiometry in a gradient of lake mixing depths, Limnol. Oceanogr. 51 (2006), pp. 1898-1905.

[3] G. BRATBAK AND T. F. Thingstad, Phytoplankton-bacteria interactions: an apparent paradox? Analysis of a model system with both competition and commensalism, Marine EcologyProgress Series, 25 (1985), pp. 23-30.

[4] C. T. Codeço And J. P. Grover, Competition along a spatial gradient of resource supply: A microbial experimental model, Am. Nat. 157 (2001), pp. 300-315.

[5] J. P. Connolly, R. B. Coffin And R. E. Landeck, Modeling carbon utilization by bacteria in natural water systems, In: Modeling the Metabolic and Physiologic Activities of Microorganisms, ed. C Hurst, John Wiley, New York, (1992), pp. 249-276.

[6] J. B. Cotner And B. A. Biddanda, Small players, large role: microbial influence on autoheterotrophic coupling and biogeochemical processes in aquatic ecosystems, Ecosystems, 5 (2002), pp. 105-121.

[7] J. B. Cotner, Personal Communication, 2006.

[8] S. DieHL, Phytoplankton, light, and nutrients in a gradient of mixing depths: Theory, Ecology 83 (2002), pp. 386-398.

[9] S. Diehl, S. A. Berger AND R. WÖHRL, Flexible algal nutrient stoichiometry mediates environmental influences on phytoplankton and its abiotic resources, Ecology 86 (2005), pp. 2931-2945.

[10] S. Diehl, Personal Communication, 2006.

[11] W. T. Edmondson, The Uses of Ecology: Lake Washington and Beyond, University of Washington Press, Seattle (1991).

[12] J. J. Elser, D. Dobberfuhl, N. A. MacKay And J. H. Schampel, Organism size, life history, and N:P stoichiometry: Towards a unified view of cellular and ecosystem processes, BioScience, 46 (1996), pp. 674-684.

[13] P. A. Del Giorgio AND J. J. COLE, Bacterial growth efficiency in natural aquatic systems, Annu. Rev. Ecol. Syst., 29 (1998), pp. 503-541.

[14] J. P. Grover, Resource Competition, Population and Community Biology Series, Chapman\&Hall (1997).

[15] J. P. Grover, Stoichiometry, herbivory and competition for nutrients: simple models based on planktonic ecosystems, J. Theor. Biol., 214 (2002), pp. 599-618. 
[16] J. P. Grover, Personal Communication, 2006.

[17] D. O. Hessen and B. BJerkeng, A model approach to planktonic stoichiometry and consumerresource stability, Freshwater Biol. 38 (1997), pp. 447-472.

[18] D. O. Hessen, K. Nygaard, K. Salonen and A. Vähätalo, The effect of substrate stoichiometry on microbial activity and carbon degradation in humic lakes, Environ. Int. 20 (1994), pp. 67-76.

[19] A. J. Horne and C. R. Goldman, Limnology, 2nd edition, McGraw-Hill Co., New York (1994).

[20] J. Huisman and F.J. Weissing, Light-limited growth and competition for light in well-mixed aquatic environments: an elementary model, Ecology 75 (1994) pp. 507-520.

[21] J. Huisman And F. J. Weissing, Competition for nutrients and light in a mixed water column: A theoretical analysis, Am. Nat. 146 (1995), pp. 536-564.

[22] C. A. Klausmeier and E. Litchman, Algal games: The vertical distribution of phytoplankton in poorly mixed water columns, Limnol. Oceanogr., 46 (2001), pp. 1998-2007.

[23] C. A. Klausmeier, E. Litchman and S.A. Levin, Phytoplankton growth and stoichiometry under multiple nutrient limitation, Limnol. Oceanogr., 49 (2004), pp. 1463-1470.

[24] Y. Kunang, J. Huisman And J. J. Elser, Stoichiometric plant-herbivore Models and their interpretation, Math. Biosc. and Eng., 1 (2004), pp. 215-222.

[25] L. D. J. Kuijper, B. W. Kooi, T. R. Anderson and S. A. L. M. Kooijman, Stoichiometry and food-chain dynamics, Theor. Pop. Biol., 66 (2004), pp. 323-339.

[26] J. D. Logan, A. Joern And W. Wolesensky, Mathematical model of consumer homeostasis control plant-herbivore dynamics, Math. and Comp. Modelling, 40 (2004), pp. 447-456.

[27] I. Loladze, Y. KuAng and J. J. Elser, Stoichiometriy in producer-grazer systems: linking energy flow with element cycling, Bull. Math. Biol. 62 (2000), pp. 1137-1162.

[28] I. Loladze, Y. Kuang, J. J. Elser and W. F. Fagan, Coexistence of two predators on one prey mediated by stoichiometry, Theor. Popul. Biol., 65 (2004), pp. 1-15.

[29] W. Makino, J. B. Cotner, R. W. Sterner and J. J. Elser, Are bacteria more like plants or animals? Growth rate and resource dependence of bacterial C:N:P stoichiometry, Functional Ecology, 17 (2003), pp. 121-130.

[30] W. A. Nelson, E. McCauley and F. J. Wrona, Multiple dynamics in a single predatorprey system: experimental effects of food quality. Proc. R. Soc. Lond. B., 268 (2001), pp. 1223-1230.

[31] J. A. Newman, D. J. Gibson, E. Hickam, M. Lorenz, E. Adams, L. Bybee and R. Thompson, Elevated carbon dioxide results in smaller populations of the bird cherry-oat aphid Rhopalosiphum padi, Ecol. Entom., 24 (1999), pp. 486-489.

[32] Y. Nishimura, C. Kim, And T. NAGATA, Vertical and seasonal variations of bacterioplankton subgroups with different nucleic acid contents: possible regulation by phosphorus, Applied and Environmental Microbiology, 71 (2005), pp. 5828-5836.

[33] H. L. Sмiтh, Monotone Dynamical Systems, an Introduction to the Theory of Competitive and Cooperative Systems, American Mathematical Society, Mathematical Surveys and Monographs (1995).

[34] H. L. Smith AND B. Li, Competition for essential resources: A brief review, Fields Institute Communications, 36 (2003), pp. 213-227.

[35] H. L. Smith And P. Waltman, The Theory of the Chemostat: Dynamics of Microbial Competition, Cambridge University Press (1994).

[36] H. L. Smith and P. Waltman, Perturbation of a Globally Stable Steady State, Proc. Amer. Math. Soc., 127 (1999), pp. 447-453 (electronic).

[37] R. W. Sterner And J. J. Elser, Ecological Stoichiometry - The biology of elements from molecules to the biosphere, Princeton University Press (2002).

[38] R. W. Sterner, J. J. Elser, E. J. Fee, S. J. Guildford and T. H. Chrzanowski, The light: nutrient ratio in lakes: The balance of energy and materials affects ecosystem structure and process, Am. Nat. 150 (1997), pp. 663-684.

[39] H. R. Thieme, Mathematics in Population Biology, Princeton Series in Theoretical and Computational Biology, Princeton University Press (2003).

[40] H. R. Thieme, Persistence under relaxed point-dissipativity (with application to an epidemic model), SIAM J. Math. Anal. 24 (1993), pp. 407-435.

\section{Appendix}


Proof of Theorem 1: Positivity holds obviously for the system. Let $R=A Q+$ $P+\theta B$, which is the total phosphorus in system $(2.2)$. Then

$$
\frac{d R}{d t}=\frac{D}{z_{m}}\left(P_{i n}-R\right)-\left(l_{m}+\frac{\nu}{z_{m}}\right) A Q-\theta\left(\mu_{r}+\mu_{g}\right) B \leq \frac{D}{z_{m}}\left(P_{i n}-R\right)
$$

which implies

$$
R^{\infty}=\limsup _{t \rightarrow \infty} R(t) \leq P_{\text {in }} \quad \text { and } \quad R(t) \leq \max \left\{P_{\text {in }}, R(0)\right\} .
$$

Since all the variables are positive and $Q_{m} \leq Q \leq Q_{M}$, we have

$$
A^{\infty}=\limsup _{t \rightarrow \infty} A(t) \leq \frac{P_{i n}}{Q_{m}} \quad \text { and } \quad A(t) \leq \frac{1}{Q_{m}} \max \left\{P_{i n}, R(0)\right\} .
$$

Notice that

$$
\frac{d C}{d t} \leq \mu_{A} A-\frac{D}{z_{m}} C \leq \frac{\mu_{A}}{Q_{m}} \max \left\{P_{i n}, R(0)\right\}-\frac{D}{z_{m}} C
$$

we have

$$
C(t) \leq \max \left\{\frac{z_{m} \mu_{A}}{D Q_{m}} \max \left\{P_{i n}, R(0)\right\}, C(0)\right\}=\max \left\{\frac{z_{m} \mu_{A} P_{i n}}{D Q_{m}}, \frac{z_{m} \mu_{A} R(0)}{D Q_{m}}, C(0)\right\} .
$$

Hence, for given initial conditions, $C(t)$ is bounded. Therefore, all the variables are bounded. It is easy to show that

$$
\limsup _{t \rightarrow \infty} C(t)=C^{\infty} \leq \frac{z_{m} \mu_{A}}{D} A^{\infty} \leq \frac{z_{m} \mu_{A}}{D} \frac{P_{i n}}{Q_{m}}=\frac{z_{m} \mu_{A} P_{i n}}{D Q_{m}} .
$$

Consequently, the bacteria-algae system (2.2) is dissipative and

$$
\wp=\left\{(A, Q, P, B, C) \in \Omega \mid A Q+P+\theta B \leq P_{i n}, C \leq \frac{z_{m} \mu_{A} P_{i n}}{D Q_{m}}\right\}
$$

is a global attracting region for the system.

Proof of Theorem 2: At $E_{0}$, the Jacobian matrix is

$$
J\left(E_{0}\right)=\left(\begin{array}{ccc}
\Psi(0, \hat{Q}) & 0 & 0 \\
+ & \lambda_{1} & + \\
- & 0 & \lambda_{2}
\end{array}\right)
$$

Where $\lambda_{1}$ and $\lambda_{2}$ are negative numbers. It is easy to see that the eigenvalues of $J\left(E_{0}\right)$ are $\Psi(0, \hat{Q}), \lambda_{1}$ and $\lambda_{2} . \quad R_{0}<1$ implies $\Psi(0, \hat{Q})<0$. Hence $E_{0}$ is locally asymptotically. $R_{0}>1$ implies $\Psi(0, \hat{Q})>0$, which implies that $E_{0}$ is unstable.

For the case $R_{0}>1$, let $x=(A, Q, P)$ and $x^{\prime}=F(x)$, then $F: \mathbb{R}_{+}^{3} \longrightarrow \mathbb{R}^{3}$ is locally Lipschitzian. Let $\Omega_{1}=\{(A, Q, P) \in \Omega \mid A \neq 0\}, \Omega_{2}=\{(A, Q, P) \in \Omega \mid A=$ $0\}$, then $\Omega=\Omega_{1} \cup \Omega_{2}, \Omega_{1} \cap \Omega_{2}=\emptyset$, with $\Omega_{2}$ being a closed invariant subset of $\mathbb{R}_{+}^{3}$ and $\Omega_{1}$ positively invariant. $E_{0}$ is the only equilibrium in $\Omega_{2}$. It is easy to show that solution that starts in $\Omega_{2}$ converges to $\left\{E_{0}\right\}$.

The singleton set $\left\{E_{0}\right\}$ is a uniform weak repeller for $\Omega_{1}$ when $R_{0}>1$ and an isolated invariant set in $\Omega([39])$. It is acyclic in $\Omega_{2}$. Hence $\Omega_{2}$ is a uniform strong 
repeller for $\Omega_{1}$ and there exists an equilibrium $x^{*} \in \Omega_{1}, F\left(x^{*}\right)=0$ ([40]). The first conclusion implies $A$ is uniformly persistent.

We are now ready to establish uniqueness of $E^{*}$. $E^{*}$ satisfies

$$
\begin{aligned}
\mu_{A}\left(1-\frac{Q_{m}}{Q}\right) h(A)-l_{m}-\frac{\nu+D}{z_{m}} & =0, \\
\rho(Q, P)-\mu_{A} Q\left(1-\frac{Q_{m}}{Q}\right) h(A) & =0, \\
\frac{D}{z_{m}}\left(P_{i n}-P\right)-\rho(Q, P) A & =0 .
\end{aligned}
$$

By simple eliminations, we see that

$$
P=P_{i n}-\frac{z_{m}}{D}\left(l_{m}+\frac{\nu+D}{z_{m}}\right) A Q=P_{i n}-\left(\frac{z_{m}}{D} l_{m}+\frac{\nu+D}{D}\right) A Q .
$$

By substitution this into the equation (6.1), we have

$$
A=\frac{M+P_{i n}-\frac{\rho_{m}}{\left(l_{m}+\frac{\nu+D}{z_{m}}\right) Q} \frac{Q_{M}-Q}{Q_{M}-Q_{m}} P_{i n}}{\left(\frac{z_{m}}{D}\left(l_{m}+\frac{\nu+D}{z_{m}}\right) Q-\rho_{m} \frac{z_{m}}{D} \frac{Q_{M}-Q}{Q_{M}-Q_{m}}\right.} \equiv F(Q) .
$$

Therefore

$$
\Phi(Q) \equiv \Psi(F(Q), Q)=\mu_{A}\left(1-\frac{Q_{m}}{Q}\right) h(F(Q))-l_{m}-\frac{\nu+D}{z_{m}}=0 .
$$

We will show that $\Phi(Q)=0$ has a unique positive solution. To this end, we show that $F(Q)$ is decreasing in $Q$. Notice that

$$
F(x)=\frac{a-\left(\frac{b}{x}-c\right)}{d x-(e-f x)}=\frac{(a+c) x-b}{(d+f) x^{2}-e x}
$$

where $a=M+P_{i n}, b=\frac{\rho_{m}}{l_{m}+\frac{\nu+D}{z_{m}}} \frac{Q_{M}}{Q_{M}-Q_{m}} P_{i n}, c=\frac{\rho_{m}}{l_{m}+\frac{\nu+D}{z_{m}}} \frac{1}{Q_{M}-Q_{m}} P_{i n}$, $d=\frac{z_{m}}{D}\left(l_{m}+\frac{\nu+D}{z_{m}}\right), e=\rho_{m} \frac{z_{m}}{D} \frac{Q_{M}}{Q_{M}-Q_{m}}, f=\rho_{m} \frac{z_{m}}{D} \frac{1}{Q_{M}-Q_{m}}$. We have

$$
F^{\prime}(x)=\frac{-(a+c)(d+f) x^{2}+2 b(d+f) x-b e}{\left((d+f) x^{2}-e x\right)^{2}} \equiv \frac{G(x)}{\left((d+f) x^{2}-e x\right)^{2}} .
$$

Observe that

$$
\Delta=[2 b(d+f)]^{2}-4(a+c)(d+f) b e=4 b(d+f)[b(d+f)-e(a+c)]<0
$$

since $b(d+f)-e(a+c)=-\rho_{m} \frac{z_{m}}{D} \frac{Q_{M}}{Q_{M}-Q_{m}} M<0$. Therefore $G(x)=-(a+c)(d+$ $f) x^{2}+2 b(d+f) x-b e<0$. Therefore $F(x)$ is strictly decreasing in $x$. As a result, the uniqueness of $E^{*}$ holds.

Assume now that $R_{0}<1$. If we have a positive equilibrium, then $\bar{Q}>\hat{Q}$ since $\Phi(\hat{Q})=\Psi(0, \hat{Q})<0$. Observe that since $\bar{P}<M+\bar{P}$, we need only

$$
\left(l_{m}+\frac{\nu+D}{z_{m}}\right) \bar{Q}<\rho_{m} \frac{Q_{M}-\bar{Q}}{Q_{M}-Q_{m}}
$$




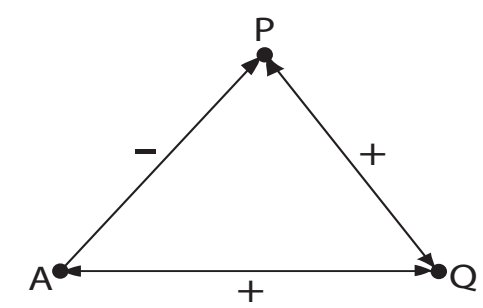

FIG. 6.2. Graph of algae system (3.1) to check that system is competitive. This is observed from the Jacobian matrix of system (3.1) in the proof of Theorem 2.

to guarantee that $\bar{P}>0$. To ensure $\bar{A}>0$, due to (6.4), we need the more restrictive condition

$$
\left(\frac{z_{m}}{D} l_{m}+\frac{\nu+D}{D}\right) \bar{Q}-\rho_{m} \frac{z_{m}}{D} \frac{Q_{M}-\bar{Q}}{Q_{M}-Q_{m}}<-M\left(\frac{z_{m}}{D} l_{m}+\frac{\nu+D}{D}\right) \bar{Q} / P_{i n} .
$$

Hence $\bar{A}>0$ will ensure $\bar{P}>0$. The previous inequality implies that

$$
\bar{Q}<\frac{\beta\left(P_{i n}\right) Q_{M}}{\beta\left(P_{i n}\right)+\left(l_{m}+\frac{\nu+D}{z_{m}}\right)} .
$$

Recall that $R_{0}<1$ implies that $\mu_{A}\left(1-Q_{m} / \hat{Q}\right) h(0)<l_{m}+\frac{\nu+D}{z_{m}}$ and

$$
\hat{Q}=\frac{\beta\left(P_{i n}\right) Q_{M}+\mu_{A} Q_{m} h(0)}{\beta\left(P_{i n}\right)+\mu_{A} h(0)} .
$$

Hence

$$
\bar{Q}-\hat{Q}<\frac{\beta\left(P_{i n}\right) Q_{M}}{\beta\left(P_{i n}\right)+\left(l_{m}+\frac{\nu+D}{z_{m}}\right)}-\frac{\beta\left(P_{i n}\right) Q_{M}+\mu_{A} Q_{m} h(0)}{\beta\left(P_{i n}\right)+\mu_{A} h(0)} .
$$

Simple computation shows that

$$
\bar{Q}-\hat{Q}<-\frac{\mu_{A} h(0) Q_{m}\left(\beta\left(P_{i n}\right)+\mu_{A} h(0)\right)}{\left(\beta\left(P_{i n}\right)+\left(l_{m}+\frac{\nu+D}{z_{m}}\right)\right)\left(\beta\left(P_{i n}\right)+\mu_{A} h(0)\right)}<0,
$$

a contradiction to $\bar{Q}>\hat{Q}$.

We now proceed to show that $E_{0}$ is globally asymptotically stable when $R_{0}<1$. The Jacobian matrix of system (3.1) has the structure:

$$
J=\left(\begin{array}{ccc}
* & + & 0 \\
+ & * & + \\
- & + & *
\end{array}\right)
$$

which is sign-stable for the off-diagonal elements. According to the graph in Fig.6.2, every closed loop has an even number of edges with + signs, thus the system (3.1) is monotone (p50-51, [33]) in $\Omega$ with respect to the order defined by

$$
K_{m}=\left\{(A, Q, P) \in \mathbb{R}^{3} \mid A \geq 0, Q \leq 0, P \geq 0\right\} .
$$

An application of monotone dynamical system theory (Prop. 4.3, p44, [33]) yields the statement that if system (3.1) has a positive periodic solution in $\Omega$, then it contains 
an equilibrium in $\Omega$. However, we have shown there is no positive equilibrium $E^{*}$ when $R_{0}<1$. Hence system (3.1) has no positive periodic solution in $\Omega$. By the Poincaré-Bendixson theory for the monotone algae system and the local stability of $E_{0}$, we see that $E_{0}$ is globally asymptotically stable.

Proof of TheOREM 3: An application of the quasi-steady state approximation for the cell quota equation yields

$$
\tilde{Q}=\frac{Q_{M} \beta(P)+Q_{m} \mu_{A} h(A)}{\beta(P)+\mu_{A} h(A)} \equiv \gamma(A, P)
$$

which is increasing in both $A$ and $P$, with $\gamma(A, P) \in\left(Q_{m}, Q_{M}\right)$. The system (3.1) is then reduced to a two dimensional system:

$$
\left\{\begin{array}{l}
\frac{d A}{d t}=\mu_{A} A\left(1-\frac{Q_{m}}{\gamma(A, P)}\right) h(A)-l_{m} A-\frac{\nu+D}{z_{m}} A \equiv F_{1}(A, P), \\
\frac{d P}{d t}=\frac{D}{z_{m}}\left(P_{i n}-P\right)-\mu_{A}\left(\gamma(A, P)-Q_{m}\right) h(A) A \equiv F_{2}(A, P) .
\end{array}\right.
$$

There are still two equilibria: $\tilde{E}_{0}=\left(0, P_{i n}\right)$ and $\tilde{E}^{*}=(\bar{A}, \bar{P})$. All the theorems above for system (3.1) hold for system (6.5). Choose Dulac function $\delta(A, P)=1 / A$. Then

$$
\begin{gathered}
\frac{\partial\left(\delta F_{1}\right)}{\partial A}=\partial\left[\mu_{A}\left(1-\frac{Q_{m}}{\gamma(A, P)}\right) h(A)-l_{m}-\frac{\nu+D}{z_{m}}\right] / \partial A \\
=\partial\left[\mu_{A} \frac{\left(Q_{M}-Q_{m}\right) \beta(P) h(A)}{Q_{M} \beta(P)+Q_{m} \mu_{A} h(A)}\right] / \partial A<0, \\
\frac{\partial\left(\delta F_{2}\right)}{\partial P}=\partial\left[\frac{D}{z_{m}}\left(P_{i n}-P\right) / A-\mu_{A}\left(\gamma(A, P)-Q_{m}\right) h(A)\right] / \partial P<0 .
\end{gathered}
$$

Therefore $\frac{\partial\left(\delta F_{1}\right)}{\partial A}+\frac{\partial\left(\delta F_{2}\right)}{\partial P}<0$. By Poincaré-Bendixson Theory, the positive equilibrium $\tilde{E}^{*}$ is globally asymptotically stable for the system $(6.5)$ when $R_{0}>1$.

Proof of TheOrem 4: The system (3.1) satisfies the conservation principle as follows: $\frac{d(P+A Q)}{d t}=\frac{D}{z_{m}}\left(P_{i n}-P\right)-\left(l_{m}+\frac{\nu+D}{z_{m}}\right) A Q=\frac{D}{z_{m}}\left(P_{i n}-P\right)-\frac{D}{z_{m}} A Q=$ $\frac{D}{z_{m}}\left[P_{i n}-(P+A Q)\right]$; then, all solutions of system (3.1) asymptotically approach the surface $P+A Q=P_{\text {in }}$ as $t \rightarrow \infty$. We only need to show $E^{*}$ is globally asymptotically stable on the surface $P+A Q=P_{i n}$, which is the limiting case of system (3.1). The whole system is reduced to be a planar system on the surface; then, we can prove global stability on the surface as theorem 3, when $R_{0}>1$. According to Smith and Waltman (1994), $E^{*}$ is also globally asymptotically stable for the system (3.1) when $R_{0}>1$.

For convenience, we use the same notations $\Omega, \Omega_{1}, \Omega_{2}, \wp, F, M$ etc for system (2.2) in the following proofs as we did for system (3.1). Although they are different 
from those used for system (3.1), they play similar roles for system (2.2).

Proof of Theorem 5: For system (2.2), consider the total carbon $T=A+B / r+C$. Then $\frac{d T}{d t}=\mu_{A} A h(A)-\frac{D}{z_{m}} T-\left(l_{m}+\frac{\nu}{z_{m}}\right) A-\frac{\mu_{r}+\mu_{g}}{r} B \leq \mu_{A} A h(A)-\frac{D}{z_{m}} T$, which gives us $\frac{d T}{d t} \leq \mu_{A} T h(T)-\frac{D}{z_{m}} T$, since $A h(A)$ is increasing in $A$. By the condition $\mu_{A} h(0)<\frac{D}{z_{m}}$, and $h(A)$ is decreasing in $A$, we have $\mu_{A} h(T)-\frac{D}{z_{m}} \leq \mu_{A} h(0)-\frac{D}{z_{m}}<0$, which implies $T \rightarrow 0$ as $t \rightarrow \infty$. Together with positivity of all the variables, we have $\lim _{t \rightarrow \infty} A(t)=\lim _{t \rightarrow \infty} B(t)=0$ for all nonnegative initial conditions, that is, both algae and bacteria go extinct. 